\title{
Peertechz
}

\section{A virtual imprint of the artificial neural networks}

Received: 06 March, 2021

Accepted: 20 March, 2021

Published: 22 March, 2021

*Corresponding author: Gaurav Kumar, Department of Mechanical Engineering, School of Engineering, Cochin University of Science and Technology, Kerala, India, Tel: +919461132772; E-mail:me.gaurav@cusat.ac.in; gauravkumar.bokaro@gmail.com

ORCID: https://orcid.org/0000-0003-1211-9386

https://www.peertechzpublications.com

\section{Check for updates}

Technology, Kerala, India

\section{Abstract}

Artificial neural systems ordinarily alluded because the neural systems are the information or signal process scientific demonstrate that is supported the natural nerve cell. A neural network is also complicated structure that comprise a bunch of interconnected neurons which provides an extremely energizing choices for complex drawback understanding and different application which may play crucial half in today's engineering science field therefore researchers from the various teach are designing the counterfeit neural systems to fathom the problems of pattern acknowledgment, forecast, improvement, related memory and management. During this paper I've bestowed the basic have faith in of the counterfeit neural organize, its characteristics and its applications.

\section{Introduction}

Deep learning is one amongst the most well-liked topics within the market. Most things in our way of life use deep learning. Deep learning is nothing however a broader a part of computer science and machine learning. It created the human work a lot of easier. Deep learning is nothing however an oversized neural network. In Deep learning, we tend to learn the machine and how it replicates the brain.

\section{Neural networks}

Basically, neural network could be a circuit or network of neurons that are accustomed share information. Once the neural network is created of real biological neurons, then it's known as Biological Neural Network. And once the neural network consists of artificial neurons, and then it's known as Artificial Neural Network. Artificial Neural Networks (ANN), additionally known as neural networks, are nothing however computing systems whose plan is taken from the brain. Neural network could be a system that's designed to figure like human brains. The purposeful unit in Deep learning is neural networks [1-6].

\section{Artificial neural networks}

An artificial neural network is basically a process network supported biological neural networks. These models aim to duplicate the complicated network of neurons in our brains (because imagine what a laptop will do if it operates like our brains). Merely place Artificial Neural Networks are a collection of information mining mechanisms that try and mimic the educational method of an individual's brain. The thought of ANNs is predicated on the idea that operating of human brain by creating the correct connections, are often imitated exploitation semiconducting material and wires as living neurons and dendrites. The human brain consists of eightysix billion nerve cells known as neurons. They're connected to different thousand cells by Axons. Stimuli from external surroundings or inputs from sensory organs are accepted by dendrites. These inputs produce electrical impulses that quickly travel through the neural network. A nerve cell will then send the message to different nerve cell to handle the problem or doesn't send it forward.

ANNs are composed of multiple nodes that imitate biological neurons of human brain. The neurons are connected by links and that they act with one another. The nodes will take input file and perform easy operations on the information. The results of these operations are passed to different neurons. The output at every node is termed its activation or node worth. Each link is related to weight. ANNs are capable of learning that takes place by neutering weight values. The subsequent illustration shows an easy an easy.

Neural Network is simply sort of a web site network of interconnected neurons which maybe millions in variety. 


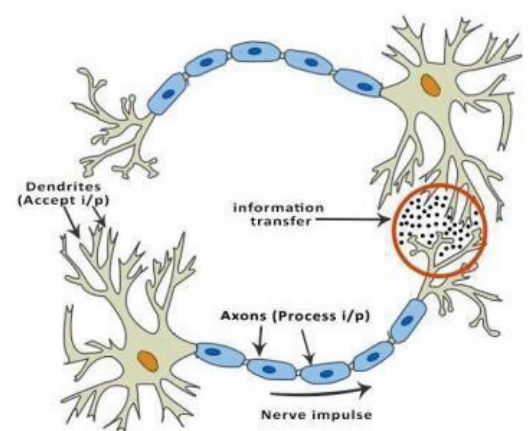

With the assistance of those interconnected neurons all the data processing is being done in body and therefore the best example of data processing is human or animal's body. Right now, artificial neural networks are the cluster of the primitive artificial neurons.

This clustering happens by creating layers that are at that time associated to one another. However, these layers interface is that the different portion of the "craftsmanship" of engineering systems to resolve the complicated issues of the real world. therefore, neural systems, with their a lot of grounded capability to derive which means from difficult or inexact information, are often utilized to disengage styles and observe trends that are additionally complicated to be taken note by either folks or different laptop procedure [7-11].

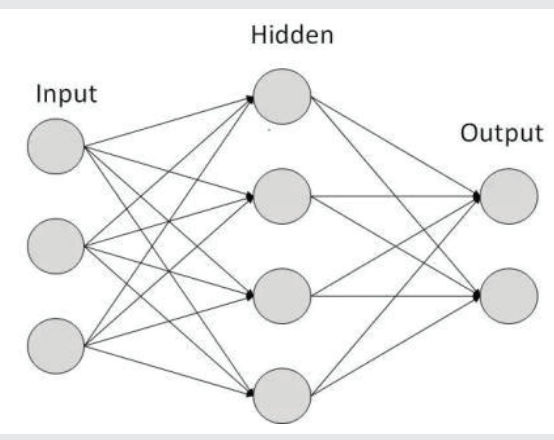

\section{Types of ANNs}

\section{There are two Artificial Neural Network topologies}

- $\quad$ Feed Forward ANN

- $\quad$ Feed Back ANN

Feed forward ANN: During this ANN, the knowledge flow is simplex. A unit sends data to different unit from that it doesn't receive any data. There are not any feedback loops. They're employed in pattern generation / recognition / classification. They need fastened inputs and outputs.

Feed back ANN: As compared to the Feed Forward ANN the feedback loops are allowed. They are employed in content available reminiscences and are utilized by the Inner framework mistake changes. A feed-forward organize may well be a basic neural organize comprising of Associate in Nursing input layer, a yield layer and one or a lot of layers of neurons. In
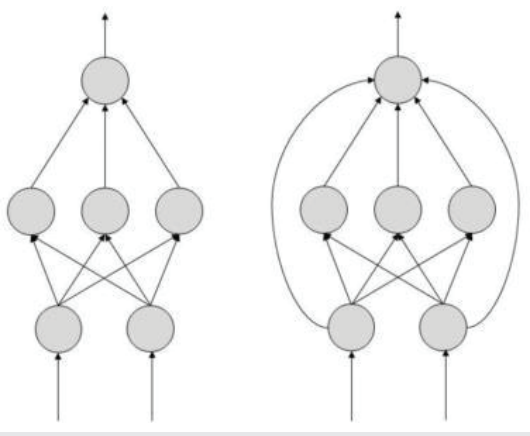

the topology diagrams shown, every arrow represents an association between 2 neurons and indicates the pathway for the flow of knowledge. Every association encompasses a weight, Associate in nursing the whole number that controls the signal between the 2 neurons. If the network generates a "good or desired" output, there's no have to be compelled to change the weights. However, if the network generates a "poor or undesired" output or a blunder, then the system alters the weights so as to enhance resultant results.

\section{ML in ANNs}

ANNs are capable of learning and that they have to be compelled to be trained. There are many learning methods:

- Supervised learning: It involves an instructor that's scholar than the ANN itself. As an example, the teacher feeds some example information concerning that the teacher already is aware of the answers. As an example, pattern recognizing. The ANN comes up with guesses whereas recognizing. Then the teacher provides the ANN with the answers. The network then compares it guesses with the teacher's "correct" answers and makes changes in step with errors.

- Unsupervised Learning: it's needed once there's no example information set with acknowledged answers. As an example, checking out a hidden pattern. During this case, cluster i.e. dividing a collection of components into teams in step with some unknown pattern is disbursed supported the \{present\} information sets present.

- Reinforcement Learning: This strategy designed on observation. The ANN makes a choice by perceptive its surroundings. If the observation is negative, the network adjusts its weights to be ready to build a unique needed call consequent time.

\section{Applications of ANN}

The real time applications of Artificial Neural Networks are:

- Functional approximation, together with statistic prediction and modeling.

- Decision control- Associate in nursing an incoming decision (speaker-ON) with a swipe of the hand whereas driving. 
- Classification, together with pattern and sequence recognition, pattern detection and consecutive deciding.

- Skip tracks or management volume on your media player exploitation easy hand motions.

- Processing, together with filtering, clustering, blind signal separation and compression.

- Scroll web content, or in Associate in nursing eBook with easy left and hand gestures, this can be ideal once touching the device could be a barrier like wet hands are wet, with gloves, dirty etc.

- Application areas of ANNs embody system identification and management (vehicle management, method control), game-playing and deciding (chess, racing), pattern recognition (radar systems, face identification, beholding, etc.), sequence recognition (gesture, speech, written text recognition), diagnosing, money applications, data processing (or data discovery in databases, "KDD").

- Another fascinating use is once exploitation the Smartphone as a media hub; a user will dock the device to the TV and watch content from the device- whereas dominant the content in a very touch-free manner from a way.

- Recently, I personally have used ANN in the field of biomass briquettes and COVID analysis.

\section{Conclusion}

Neural networks are appropriate for predicting statistic in the main be- reason for learning solely from examples, with none have to be compelled to add further data which will bring a lot of confusion than prediction impact. Neural networks are ready to generalize and are immune to noise. Also, we tend to additionally recognize that these days, neural networks are used for resolution several business issues like sales statement, client analysis, information validation, and risk management. As an example, we tend to apply neural networks for timeseries productions, anomaly detection in information, and linguistic communication understanding.

Neural networks will have several different applications like text classification, data extraction, linguistic sparsing, question respondent, paraphrases detection, language generation, multi document report, computational linguistics, and speech and character recognition. Neural networks are tons quicker within the future, and neural network tools will get embedded in each style surface.

\section{References}

1. Haykin S (1999) Neural Networks A Comprehensive Foundation. 2d edition, Pearson Education. Link: http://bit.ly/2PjxtJi
2. Sonali Ms. Maind B (2014) analysis Paper on Basic of Artificial Neural Network. International Journal on Recent and Innovation Trends in Computing and Communication Volume: two Issue: one. Gregorian calendar month.

3. Vidushi (2012) International Journal of Advanced analysis in engineering science and code Engineering two 278-284.

4. Concerning Feed Back Network from web site. Link: http://bit.ly/392jcOp

5. Gopal S (1988) Artificial Neural Networks for abstraction information Analysis. Boston.

6. Li EY (1994) Artificial Neural Networks and their Business Applications. Taiwan. Information \& Management 27: 303-313. Link: http://bit.ly/3tHryfJ

7. Stergiou C, Siganos D Neural Networks. Link: https://bit.ly/3tNly5n

8. Concerning Neural Network from web site.

9. Jha GK Artificial Neural Network and its Applications. IARI New Delhi. Link: https://bit.ly/2OLK1sZ

10. Kumar G, Thampi BSG, Mondal PK (2020) Predicting Performance of Briquette Made from Millet Bran: A Neural Network Approach. Adv J Grad Res 9: 1-13. Link: https://bit.ly/3c9NzOg

11. Kumar G, Kumar RR (2020) A correlation study between meteorological parameters and COVID-19 pandemic in Mumbai, India. Diabetes \& Metabolic Syndrome: Clinical Research \& Reviews 14: 1735-1742. Link: http://bit.ly/311ht14

Discover a bigger Impact and Visibility of your article publication with

\section{Peertechz Publications}

\section{Highlights}

* Signatory publisher of ORCID

* Signatory Publisher of DORA (San Francisco Declaration on Research Assessment)

* Articles archived in worlds' renowned service providers such as Portico, CNKI, AGRIS, TDNet, Base (Bielefeld University Library), CrossRef, Scilit, J-Gate etc.

* Journals indexed in ICMJE, SHERPA/ROMEO, Google Scholar etc.

- OAl-PMH (Open Archives Initiative Protocol for Metadata Harvesting)

* Dedicated Editorial Board for every journal

* Accurate and rapid peer-review process

* Increased citations of published articles through promotions

* Reduced timeline for article publication

Submit your articles and experience a new surge in publication services (https://www.peertechz.com/submission).

Peertechz journals wishes everlasting success in your every endeavours.

Copyright: (c) 2021 Kumar G. This is an open-access article distributed under the terms of the Creative Commons Attribution License, which permits unrestricted use, distribution, and reproduction in any medium, provided the original author and source are credited. 